\title{
O PÓDIO É DELAS: AQUI A MULHER TEM VOZ E ESPAÇO NO ESPORTE
} O PODIO É DELAS: HERE THE WOMAN HAS VOICE AND SPACE IN SPORTS

\author{
Andreia Sena Maidana' ${ }^{1}$ Renata Marinho Medina ${ }^{2}$, Tamara Finardi3 e Caroline Siqueira Flores ${ }^{4}$
}

RECEBIDO EM: 10/06/2017 | APROVADO EM: 22/07/2017

DOI: $10.5902 / 2317175827616$

\section{RESUMO}

O projeto O Pódio É Delas, que vem sendo veiculado em formato de programa radiofônico, apresenta como proposta um modelo alternativo de programação de jornalismo, direcionado para as mulheres no esporte. O programa busca dar voz às mulheres de uma maneira plural, com produção totalmente local. O modelo é proposto a partir do debate de Gênero e representação feita pela mídia tradicional acerca da imagem das mulheres no esporte. Desta forma, o programa abre espaço para empoderar as mulheres e demonstrar que lugar de Mulher é no esporte e onde ela quiser estar. Por isso, O Pódio É Delas é um projeto no qual as vozes de mulheres ligadas ao mundo esportivo têm espaço, para que suas lutas e conquistas finalmente possam ser ouvidas. A programação contempla nesse modelo programas com temáticas esportivas variadas, justamente para atender a esse objetivo.

Palavras-chaves: Rádio Web; Jornalismo alternativo; Esporte feminino; Gênero.

1 Possui graduação em Comunicação Social - Jornalismo pela Universidade Federal de Santa Maria (2014). Graduanda em Relações Internacionais pela Universidade Federal de Santa Maria e Mestranda no Programa de Pós-Graduação em Ciências Sociais da UFSM na linha de Pesquisa Instituições e Pensamento Político. E-mail: andreiamaidana87@gmail.com.

2 Possui graduação em Jornalismo pelo Centro Universitário Franciscano(2014). E-mail: mmedina.renata@ gmail.com.

3 Bacharela em Comunicação Social - Habilitação em Jornalismo graduada pela Universidade Federal do Pampa (UNIPAMPA). Experiência em coordenaçã̃o de redações de jornais e aplicação de estratégias comunicacionais em organizações. E-mail: tamarafinardi@gmail.com.

4 Graduanda em Publicidade e Propaganda na UFSM. E-mail: fcarolsiqueira@gmail.com. 


\begin{abstract}
The project O Pódio É Delas which is being broadcast in a radio program format, presents as an alternative model of journalism programming, directed at women in sports. The program seeks to give women voice in a plural way, with a totally local production. The model is proposed from the Gender debate and on the representation made by traditional media about the image of women in sport. In this way, the program opens up space to empower women and demonstrate that Women's place is in sports and where they want to be. That is why O Pódio É Delas is a program where the voices of women linked to the sports world have space, so that their struggles and achievements can finally be heard. The program includes in this model programs with varied sports themes, precisely to meet this objective.
\end{abstract}

Keywords: Web radio; Alternative Journalism; Women's sport; Genre.

\title{
1 Introdução
}

Ainda nos dias de hoje, muitos conteúdos nos meios de comunicação, que são selecionados como pautas e são veiculados como destaque entre as várias notícias divulgadas, carecem de pluralidade de conteúdo. A representatividade e a imagem das mulheres se encaixam nessa falta de novos olhares, pois constantemente são divulgados materiais jornalísticos que as associam a estereótipos heteronormativos, as quais são estigmatizadas, por exemplo, com adjetivos ligados à fragilidade, à falta de força física, à obrigação da maternidade e à sexualização de seus corpos.

Vivendo em uma sociedade na qual a mídia influencia cada vez mais a adoção ou não de atitudes e comportamentos, o ideal passa a ser aquilo que é amplamente divulgado, criando um movimento de retroalimentação entre a mídia que oferece o que a população aparenta desejar e a população que se orienta pelas imagens e valores difundidos pela mídia escrita e falada. (ALONSO, 2004, p.93).

Nesse jogo em que a mídia muitas vezes reflete o status quo da sociedade, fazendo com que ela acabe se utilizando muito do que é divulgado, muitos estereótipos ligados às mulheres continuam se perpetuando, implicando na desvalorização de muitas atividades realizadas por elas, quando não as tenta impedir de realizá-las. Dentre essas atividades, encontram- se as práticas esportivas, conforme aponta Peres,

A mulher obteve o direito de participar efetivamente nos eventos esportivos apenas nos últimos cinquenta anos. A sua presença de modo significativo deu-se a partir de 1956, na Austrália, com uma participação de 371 mulheres contra 2.813 homens. A partir desse evento houve um considerável aumento em suas participações. (PERES, 2004, p. 53). 
Ou seja, o esporte carrega em suas origens concepções machistas, como um campo que só podia ser habitado por homens. Com o intuito de desmistificar estereótipos e promover mais visibilidade da luta e conquistas das mulheres no esporte, foi criado o projeto focado em difundir informações chamado O Pódio É Delas se concretiza através da veiculação de um programa radiofônico e de divulgação de notícias por meio de uma página no Facebook. Diante da lacuna encontrada nos veículos de comunicação, no que tange a divulgação da temática, o programa divulga exclusivamente materiais ligados a ações e iniciativas de mulheres no esporte, seja no âmbito profissional, amador ou de coordenação de projetos.

\section{Referencial teórico}

\subsection{Disputas de poder na relação entre mídia, gênero e esporte}

Ao trabalhar a partir do viés da representatividade, visibilidade e abordagem que os veículos de comunicação dão às mulheres no esporte, automaticamente a discussão ganha corpo no âmbito de gênero e mídia, relação que desnuda enraizadas disputas de poder na sociedade. A mídia massiva ainda se limita a difundir discursos fortemente baseados na binaridade de gêneros: masculino e feminino. Essa postura baseada no binarismo desvaloriza mulheres em diversos aspectos, pois reforça normas heterossexuais, conforme aponta as percepções de Judith Butler,

A instituição de uma heterossexualidade compulsória e naturalizada exige e regula o gênero como uma relação binária em que o termo masculino diferencia-se do termo feminino, realizandose essa diferenciação por meio de práticas do desejo heterossexual. (BUTLER, 2003, p.45).

A concepção promovida pelo binarismo de gênero é limitada a partir da relação determinada entre sexo biológico, gênero e desejo sexual baseado em normas heterossexuais (BUTLER, 2003). Esse binarismo também não leva em conta a abordagem de uma série de fatores relevantes nas relações sociais, como questões ligadas à classe e raça, por exemplo. Dessa forma, atitudes e identificações que extrapolam o binarismo precisaram e ainda precisam vencer diversas formas de preconceito e resistência existentes em diversas instâncias da sociedade, inclusive no que diz respeito ao espaço midiático relegado às mulheres no esporte, objetivo central do projeto apresentado neste trabalho. $\mathrm{O}$ conflito decorrente dessa luta das mulheres em quebrar padrões por meio do esporte, ocupando esse espaço recheado de jogos de interesse, é exposto por Adelman,

A persistência de grande ambivalência em relação ao significado da atividade física e esportiva das mulheres sugere que esta seja um dos mais importantes espaços de conflito relativos à definição da corporalidade feminina na atualidade, com certeza vinculado 
àquele outro campo de conflito, o da sexualidade. Portanto, torna-se interessante procurar entender exatamente o que está em jogo quando as mulheres se tornam atletas e, especificamente, atletas profissionais, identificadas com o esporte não só pelo prazer de praticá-lo, mas como forma de ganhar a vida e, ainda mais, participar de uma cultura, anteriormente masculina, que torna o/a atleta um símbolo do sucesso e da cultura nacional. Cabe perguntar em que medida a participação esportiva contribui para uma re-significação da corporalidade feminina, sendo possível também que prevaleça uma apropriação da atividade esportiva que consegue enquadrá-la dentro de padrões de normatividade social que reproduzem o controle (masculino, ou masculinista) sobre os corpos das mulheres. (ADELMAN, 2003, p.448-449).

Como a prática esportiva realizada por mulheres desafia uma série de normas impostas pelo binarismo de gênero baseado em concepções heteronormativas ainda presente na estrutura social vigente, nos deparamos com esses "ranços ideológicos" em veículos de comunicação. Isso resulta em espaços inferiores dedicados às notícias de mulheres ligadas ao esporte nos meios de comunicação, quando comparados ao destaque que é dado aos homens. Um exemplo recente é exposto pela Revista Gênero e Número (Edição 01, 2016), em uma reportagem que realizou um levantamento sobre as Olimpíadas Rio 2016 , em que $45 \%$ do total de atletas era composto por mulheres, mas estas estiveram presentes em apenas $12,6 \%$ das transmissões midiáticas durante 0 período de vigência dos jogos.

Como se não bastasse o pouco espaço disponibilizado para as atletas, muitas vezes ele ainda é ocupado com discursos que deturpam e inferiorizam suas conquistas. Essa é mais uma característica ligada ao binarismo de gênero no esporte, no qual ocorre a sexualização heteroxessual do corpo de mulheres atletas. Ao invés da validação do corpo enquanto atletas, são apontadas apenas como vitrines para atender a desejos heterossexuais, conforme aponta o escopo de pesquisas e análises de notícias realizadas por KNIJNIK E SOUZA (2004, 2007). Os pesquisadores constaram que a presença desse discurso enfraquece de uma forma geral a representatividade das atletas,

Quase sempre a cobertura da mídia sobre o esporte praticado por mulheres é acompanhada por uma trivialização e sexualização, constituindo uma negação do poder esportivo dessas muIheres. Essa negação dá suporte a idéia de que o esporte praticado por mulheres é menos poderoso e valioso do que o esporte praticado por homens. (KNIJNIK, SOUZA, p.207, 2004).

Além disso, quando o corpo das mulheres não atende às expectativas da normatividade e do controle heterossexual, ainda nos deparamos com formas de preconceito e julgamento de sua aparência física a partir de outro extremo: 
Quando as mulheres ultrapassam a linha que divide as culturas "masculinas" das "femininas" e tornam-se atletas de sucesso, seus corpos passam a ser vistos de outra forma. Os corpos dóceis e delicados, vistos outrora como uma marca da feminilidade, dão lugar a corpos musculosos obtidos de forma brutal. 0 processo de ressignificação corporal resultou em um período de adaptação social que, de certa forma, dura até hoje. (ALMEIDA, p.113, 2016).

Outro fator que não pode ser ignorado é que o esporte delegado como espaço masculino se encontra firmado em pilares ligados a interesses econômicos, ou seja, consegue se configurar por intermédio da valorização da prática esportiva realizada por homens como algo imensamente rentável e lucrativo.

A mídia e o esporte são interdependentes, e é consenso que um é indispensável para o outro, isto é, o esporte vende a mídia e a mídia vende o esporte. A relação entre o esporte e a mídia impressa também possui um benefício financeiro mútuo. (KNIJNIK E SOUZA, p.38, 2007).

Diante das problematizações expostas, ainda hoje, mulheres ligadas ao esporte se configuram como transgressoras e como símbolo de resistência., mas ainda carecem de maior espaço na mídia para que suas vozes sejam ouvidas, seus trabalhos sejam reconhecidos, suas conquistas ganhem visibilidade e seus problemas sejam amplamente discutidos. O machismo que já tentou as impedir de competir ainda existe, e se multiplica em diversas facetas, em espaços onde menos se imagina, e para combatê-lo precisamos trazer à tona essas práticas, onde quer que elas ocorram. Dentro desse contexto, veículos de comunicação alternativa emergem como diferencial, trazendo pautas e dando visibilidade para nichos da sociedade que não se enquadram na agenda baseada no Status quo.

\subsection{Mídia alternativa}

Segundo Castells (2005), a sociedade contemporânea passou por profundas mudanças estruturais, e boa parte delas podem ser associadas ao advento de novas tecnologias de comunicação e informação. Os impactos produzidos por intermédio dos meios de comunicação altamente sofisticados como a Internet têm provocado uma profunda modificação no estilo de vida, atitudes, costumes e tendências da sociedade no geral. Dentre essas mudanças, os meios de comunicação precisam reinventar-se dentro de um sistema informacional pautado pela velocidade e flexibilidade da informação, advinda de múltiplas fontes.

Com base nesse cenário, as mídias alternativas surgem como aquelas que não são entendidas como mídias tradicionais, como o jornal, a revista, o rádio ou a televisão. Essas mídias alternativas buscam pluralizar as vozes 
da sociedade ao oferecer temas, ângulos e fatos que não são compartilhados por veículos de comunicação hegemônicos que, por sua vez, procuram explorar uma realidade que lhe é benéfica econômica e politicamente, (MAZETTI, 2007). As diferenças entre mídia alternativa e mídia tradicional são, portanto, percebidas nas direções político-ideológicas que cada organização tomará, em suas propostas editoriais e o seu modo de organização. A mídia alternativa se caracteriza principalmente por suas práticas jornalísticas diferenciadas, nas quais a seleção de notícias e o enfoque dado ao conteúdo tendem a ter uma abordagem mais crítica, que contempla um cenário de representação política e social que entra em contradição com os valores e princípios predominantes na mídia tradicional, (GÓES, 2006, 2007). Isto posto, o programa O Pódio É Delas é veiculado na Rádio Web Armazém, a qual conta com programação alternativa com conteúdo totalmente local em Santa Maria, RS.

\section{Metodologia}

3.1 A práxis da comunicação alternativa na Rádio Armazém de Santa Maria - RS

A Rádio Armazém ${ }^{1}$ de Santa Maria - RS é uma emissora de rádio online que produz conteúdo colaborativo. É uma associação sem fins lucrativos de natureza cultural e informativa, que tem em seus idealizadores pessoas com longa ligação e experiência na música, comunicação e rádio. O seu principal propósito é difundir, divulgar e apoiar a cena cultural local de Santa Maria, levando aos ouvintes uma programação nova, moderna, alternativa e impulsionada pela paixão do "fazer um novo rádio". Atualmente, funciona com a colaboração de mais de 30 comunicadores que trabalham voluntariamente para divulgar e debater sobre os mais variados cenários que abarcam a sociedade, como artes, música, humor, esportes, questões políticas e sociais.

Para tanto, a Rádio Armazém possui uma grade de programação diferenciada, com programas que, no geral, se contrapõem aos conteúdos da mídia tradicional em função das temáticas veiculadas e da abordagem dada aos assuntos. Atualmente, são 17 programas ${ }^{2}$ diferentes que são apresentados ao vivo toda semana, e dentre eles, a temática das mulheres no esporte é abordada pelo programa intitulado O Pódio É Delas. A Rádio Armazém conta com o aporte de apoiadores culturais empreendedores da cidade e é apoiada também pelo Laboratório Sócio Cultural da Universidade Federal de Santa Maria. A rádio pode ser acessada por meio do site e de aplicativos específicos para celulares.

\begin{tabular}{ll}
\hline 1 & Link de acesso para a Rádio Armazém: http://radioarmazem.net/ \\
2 & Link de acesso para a programação da Rádio Armazém: http://radioarmazem.net/ - Botão pro- \\
gramação. &
\end{tabular} 
3.2 Programa O Pódio É Delas: dar voz para mulheres no esporte difundido através da Rádio Armazém

O Pódio É Delas é um projeto jornalístico que foi criado no ano de 2017 composto por quatro mulheres ligadas à comunicação com o objetivo de divulgar, valorizar, empoderar e incentivar as mulheres envolvidas em práticas esportivas, visto que, essa temática, em função de vários fatores históricos e socioculturais abordados no presente artigo, possui exímio espaço na mídia tradicional. O projeto tomou corpo e se concretizou através da Rádio Armazém, que cedeu estrutura e horário na programação radiofônica para passar a ser veiculado na web rádio. Dessa forma, também passou a reforçar sua presença por meio de uma página no Facebook, que visa promover mais interação e feedback do público que acompanha o programa, além de ser um espaço para divulgar informações complementares e estabelecer comunicação entre fontes.

O principal simbolismo do programa de rádio é criar um espaço que as vozes de mulheres, que em muitos momentos foram e são silenciadas, possam ser difundidas, expondo sua história, lutas, conquistas, dificuldades e o preconceito que ainda insiste em ser o maior obstáculo/adversário. Além disso, o programa fomenta a quebra de estereótipos ligados às mulheres, pautandose na premissa de que qualquer lugar no esporte é lugar de mulher.

Já o nome foi pensado buscando valorizar as conquistas das mulheres no âmbito esportivo, bem como expor os espaços que ainda precisam ser conquistados. Nesse sentido, o significado de Pódio é um espaço que se refere tanto a conquistas já alcançadas quanto as que ainda precisamos alcançar. Ademais, no programa as mulheres são as protagonistas do meio esportivo, em oposição a agenda da mídia tradicional, que as coloca no papel de meras coadjuvantes.

\section{Apresentação e discussão dos resultados}

4.1 Estrutura do programa radiofônico

O programa é apresentado semanalmente, ao vivo, toda quarta-feira, às $21 \mathrm{~h}$, na Rádio Armazém, e possui duração em torno de 50 minutos corridos. Aos domingos, o programa é reprisado na programação da rádio. A estrutura da condução do programa não é estática, mas possui componentes essenciais: divulgação de diversas notícias ligadas a mulheres no esporte, realização de entrevistas, e músicas de cantoras com letras que valorizem as mulheres. Cada programa é baseado em uma temática específica, como uma modalidade esportiva, por exemplo, influenciando na escolha das fontes para a entrevista. 


\subsection{Estreia do programa}

O primeiro programa ${ }^{3}$ foi veiculado ao vivo durante o Dia Internacional da Mulher, 08 de março de 2017. Diante do poder simbólico da data, o lançamento apresentou a proposta o projeto O Pódio É Delas a partir da discussão "como a mulher no esporte é retratada na mídia". Para isso, foram apresentados dados que relatam a falta de visibilidade e igualdade das mulheres no esporte. A partir disso, debateu-se o motivo para eventos de grande porte mundial não darem a devida visibilidade para as competições femininas. 0 programa contou com a presença das jornalistas Cláudia Kessler e Maria Júlia Corrêa no bate papo ao vivo no estúdio para relatar suas vivências, enquanto profissionais de comunicação no meio esportivo. Elas falaram sobre o espaço que a mídia oferece para mulheres no esporte; como é o trabalho com a temática feminina no esporte; como é a recepção dos veículos de comunicação quando se insere pautas ligadas às mulheres; qual a visão sobre o esporte feminino local; como é o relacionamento com as fontes no meio esportivo feminino, e relataram as suas opiniões sobre o que ainda falta para empoderar a mulher no esporte.

Além disso, apresentou-se uma matéria gravada com as apresentadoras Paula Cardoso e Clairene Giacobe do programa radiofônico "Agora é que são Elas", veiculado na Rádio Estação Web. As fontes foram selecionadas para falar de suas experiências e do machismo encontrado ao se posicionarem em um programa que apenas mulheres debatem e comentam o futebol. A escolha da temática se deu com o objetivo de expor a proposta do programa, bem como deixar claro que ele se amplia nos diversos problemas que mulheres enfrentam no meio esportivo, seja na condição de atleta, jornalista, comentarista ou praticante amadora, isto é, ocupando espaços que a sociedade em seus ranços heteronormativos estigmatizou como sendo exclusivamente de homens.

\subsection{Notícias}

São divulgadas notícias de mulheres ligadas ao esporte, visando critérios de noticiabilidade de atualidade e relevância. As notícias não obedecem uma localização ou temática específica, sendo apresentadas de forma variada, expondo problemas que ocorrem ao redor do mundo, evidenciando diversas competições e dando visibilidade para ações que as mulheres vem realizando nesse meio.

\subsection{Entrevistas}

As entrevistas geralmente ocorrem ao vivo e, em alguns casos são gravadas. Em alguns programas elas são apresentadas em dois formatos, mas sempre se preza pela veiculação das entrevistas, visto que elas atendem nosso 3 Link do Podcast do programa de estreia: https://www.mixcloud.com/R\%C3\%A1dioArmaz\%C3\%A9m/o-p\%C3\%B3dio-\%C3\%A9-delas-080317/ 
objetivo principal: difundir a voz das mulheres a partir de suas experiências e perspectivas. As fontes da entrevista são definidas a partir da temática de cada programa. Quando a fonte não pode comparecer no programa ao vivo a entrevista é gravada, possibilitando explorar fontes de diversas regiões do país, sendo que qualquer pessoa, de qualquer lugar, pode ter acesso ao programa através de computador e smartphone, já que se trata de uma web rádio.

Além disso, antes de introduzir a entrevista, é feita uma explanação sobre a temática, introduzindo uma situação ou falando sobre a história de algum esporte. As temáticas de cada programa são bem variadas, visando expor as várias possibilidades que as mulheres exploram no mundo esportivo, além de incentivar outras mulheres a conhecer novas práticas, desmistificando estereótipos de que mulheres não podem ocupar os mesmos espaços que os homens nos mais diversos esportes. O programa já explorou temáticas como futebol $^{4}$, futsal ${ }^{5}$, handebol ${ }^{6}$, jiu-jitsu ${ }^{7}$, canoagem ${ }^{8}$, taekwondo ${ }^{9}$, judô ${ }^{10}$, rugby ${ }^{11}$, muay thai ${ }^{12}$, esportes radicais ${ }^{13}$, mulheres na arbitragem ${ }^{14} \mathrm{e}$ a representatividade das mulheres na mídia.

\subsection{Podcast}

Todos os programas, posterior a apresentação ao vivo, são disponibilizados no formato de podcast. Dessa forma, as possibilidades de difusão das informações se ampliam, pois o ouvinte pode ouvir em diversos horários e até mais de uma vez, além de poder compartilhar o material. Os podcasts são divulgados na página que a Rádio e o programa possuem no Facebook, como forma de ampliar a divulgação dos conteúdos abordados e gerar interação com o público.

$4 \quad$ Link Podcast programa sobre futebol: https://www.mixcloud.com/R\%C3\%A1dioArmaz\%C3\%A9m/o-p\%C3\%B3dio-\%C3\%A9-delas-150317/

5 Link Podcast programa sobre futsal: https://www.mixcloud.com/R\%C3\%A1 dioArmaz\%C3\%A9m/o-p\%C3\%B3dio-\%C3\%A9-delas-com-a-equipe-femininade-futsal-fames-uni\%C3\%A3o-independente-100517/

$6 \quad$ Link Podcast sobre handebol: https://www.mixcloud.com/R\%C3\%A1dioArmaz\%C3\%A9m/o-p\%C3\%B3dio-\%C3\%A9-delas-com-handebol-feminino-sm-030517/

7 Link Podcast sobre jiu-jitsu: https://www.mixcloud.com/R\%C3\%A1dioArmaz\%C3\%A9m/o-p\%C3\%B3dio-\%C3\%A9-delas-com-mel-cueto-220317/

8 Link Podcast sobre canoagem: https://www.mixcloud.com/R\%C3\%A1dioArmaz\%C3\%A9m/o-p\%C3\%B3dio-\% \%3\%A9-delas-com-mariane-santos-050417/

9 Link Podcast sobre o taekwondo: https://www.mixcloud.com/R\%C3\%A1dioArmaz\%C3\%A9m/o-p\%C3\%B3dio-\%C3\%A9-delas-com-rejane-fidencio-260417/

10 Link Podcast sobre judô: https://www.mixcloud.com/R\%C3\%A1dioArmaz\%C3\%A9m/o-p\%C3\%B3dio-\%C3\%A9-delas-190417/

11 Link Podcast sobre rugby: https://www.mixcloud.com/R\%C3\%A1dioArmaz\%C3\%A9m/o-p\%C3\%B3dio-\%C3\%A9-delas-com-universit\%C3\%A1 rio-rugby-santa-maria-240517/

12 Link Podcast sobre Muay Thai: https://www.mixcloud.com/R\%C3\%A1dioArmaz\%C3\%A9m/o-p\% C3\%B3dio-\% C3\% A9-delas-sobre-muay-thai-com-b\% C3\%A1 rbara-marques-e-caroline-moraes/

$13 \quad$ Link Podcast sobre esportes radicais: https://www.mixcloud.com/R\%C3\%A1dioArmaz\%C3\%A9m/o-p\%C3\%B3dio-\% C3\%A9-delas-com-radical-girls-290317/

$14 \quad$ Podcast sobre mulher na arbitragem: https://www.mixcloud.com/R\%C3\%A1dioArmaz\%C3\%A9m/o-p\%C3\%B3dio-\%C3\%A9-delas-com-ma\%C3\%ADra-mastella-moreira-120417/ 


\subsection{Página no Facebook}

A página no Facebook complementa tanto a divulgação do programa radiofônico em si, quanto possibilita a criação de mais conteúdos que fogem do alcance do rádio, como fotos e notícias extras. Ela também se caracteriza pela interação, porque as publicações podem ser comentadas e compartilhadas. A interação também se dá no âmbito da possibilidade de troca de mensagens, que acabam muitas vezes sugerindo fontes e pautas. Deste modo, a página no Facebook se caracteriza como uma importante ferramenta para ampliar as possibilidades de ações e alcance do projeto O Pódio É Delas.

\section{Conclusão}

Conclui-se, a partir do projeto proposto e das discussões apresentadas, que o Programa O Pódio É Delas se torna inovador com um Jornalismo alternativo, o qual abre espaço para ouvir mulheres inseridas no meio esportivo, seja como profissão ou apenas lazer, visto que traz à tona preconceitos e obstáculos que as mulheres têm que vencer para alcançar visibilidade no esporte e todas as questões de diferenciação ao gênero feminino.

Os princípios que norteiam a proposta do programa e a pluralidade de temáticas esportivas com as mulheres, é a oportunidade para fomentar a discussão acerca da discriminação entre homens e mulheres, sobretudo dar visibilidade ao empoderamento feminino. Além do mais, a relevância do Pódio estar inserido na programação de uma Rádio Web com grade alternativa e produção no interior do Rio Grande do Sul, destaca-se em relação às mídias tradicionais dos grandes centros, que apresentam esporadicamente pautas com mulheres no esporte e, quando exploram, fazem apenas de forma superficial e, na maioria das vezes, utilizam a beleza da atleta como destaque ou abordam mulheres que já estão nas primeiras colocações, excluindo todo o histórico e obstáculos enfrentados até chegar nessa posição.

Em suma, o Pódio É Delas apresenta um olhar diferente, conta a história dessas mulheres e sua trajetória até subir no pódio, seja como profissional ou apenas simpatizante pela prática esportiva, sem deixar de apresentar e questionar os preconceitos vivenciados. O programa apresenta uma nova forma de fazer Jornalismo e empoderar a mulher no meio esportivo, pois instiga o debate sobre os problemas que enfrentam tanto na sua busca por reconhecimento no esporte como no seu dia a dia. 


\section{Referências}

ADELMAN, M. Mulheres atletas: ressignificações da corporalidade feminina. Revista Estudos Feministas, Florianópolis, v. 11, n.2, p.445 - 465, 2003. Disponível em: <https://periodicos.ufsc.br/index.php/ref/article/ view/S0104-026X2003000200006/9070> Acesso em 07/06/2017.

ALMEIDA, Caroline Soares. Belas e feras, nós e as masculinizadas: discursos, corporalidades e significações. In KESSLER, Claudia Samuel (org.). Mulheres na Área: gênero, diversidade e inserções no futebol. Porto Alegre: Editora UFRGS, 2016.

ALONSO, Luiza Klein. et al. Esporte, Imagem Corporal e Exploração de Mídia. In: III Fórum de Debates sobre Mulher \& Esporte. Mitos \& Verdades. São Paulo: USP/Faculdade de Educação Física. Fórum Internacional - 16 a 18 de setembro de 2004. p. 93-120. Disponível em: <http://www.im.br/site_1/faculdades/educacao_fisica/ estudo_muculacao/ANAIS_III_Forum_Mulher_Esporte_Mitos_e_Verdades.pdf> Acesso em 09/06/2017.

BUTLER, Judith P. Problemas de gênero: feminismo e subversão da identidade. Rio de Janeiro: Civilização Brasileira, 2003.

CASTELLS, Manuel. A Sociedade em Rede: do conhecimento à política. In: CASTELLS, Manuel; CARDOSO, Gustavo (org.). A Sociedade em Rede: Do Conhecimento à Ação Política. Imprensa Nacional - Casa da Moeda, 2006.

GÓES. Laércio Pedro Torres de. A mídia alternativa nos movimentos sociais na web. 2006. Disponível em: <http://www.facom.ufba.br/jol/pdf/2006_La\%C3\%A9rcio_A\%20m\%C3\%ADdia\%20alternativa\%20 dos\%20movimentos\%20sociais\%20na\%20Web.pdf> Acesso em 06/06/2017.

Contra-hegemonia e internet: Gramsci e a Mídia Alternativa dos Movimentos Sociais na Web. 2007. Disponível em: <http://www.facom.ufba.br/jol/pdf/2007_Laercio_Contra-hegemonia\%20e\%20 Internet\%20-\%20Laercio\%20Goes.pdf>. Acesso em 06/06/2017.

KNIJNIK, Jorge Dorfman; SOUZA, Juliana Sturmer Soares. Diferentes e desiguais: Relações de gênero na mídia esportiva brasileira; In. Antonio Carlos Simões, Jorge Dorfman Knijnik (orgs). O mundo psicossocial da mulher no esporte: comportamento, gênero, desempenho. São Paulo, Aleph, 2004 (p. 191-212).

A mulher invisível: gênero e esporte em um dos maiores jornais diários do Brasil. Rev. bras. Educ. Fís. Esp., São Paulo, v.21, n.1, p.35-48, jan./mar. 2007. Disponível em: <http://www.ip.usp.br/portal/images/ stories/Nepaids/mulher_invisvel.pdf> Acesso e, 07/06/2017.

MAZETTI, Henrique Moreira. Mídia alternativa para além da contra-informação. 2007. Disponível em: <http://www.ufrgs.br/alcar/encontros-nacionais-1/encontros-nacionais/5o-encontro-2007-1/Midia\%20 alternativa\%20para\%20alem\%20da\%20contra-informacao.pdf>. Acesso em 06/06/2017.

PERES, Waldir Pagan. et al. Esporte, Imagem Corporal e Exploração de Mídia. In: III Fórum de Debates sobre Mulher \& Esporte. Mitos \& Verdades. São Paulo: USP/Faculdade de Educação Física. Fórum Internacional - 16 a 18 de setembro de 2004. p. 42-119. Disponível em: <http://www.im.br/site_1/faculdades/educacao_fisica/ estudo_muculacao/ANAIS_III_Forum_Mulher_Esporte_Mitos_e_Verdades.pdf> Acesso em 09/06/2017.

REVISTA GÊNERO E NÚMERO. Narrativas pela equidade. Rio de Janeiro, 2016. Produção on-line. Disponível em: $<$ http://www.generonumero.media/>. 